\title{
Intersticios de la posmodernidad en el manga mexicano Drem
}

\author{
Interstices of postmodernity in the mexican manga DREM \\ Interstícios da pós-modernidade no mangá mexicano Drem
}

Sarahi Isuki Castelli Olvera

Benemérita Universidad Autónoma de Puebla, México sarahi.castelli@correo.buap.mx ares.walburga.black@gmail.com https://orcid.org/0000-0001-5955-6781

\section{Resumen}

Introducción. En este artículo se analiza el manga ${ }^{1}$ mexicano Drem, creado y publicado en México en 2008 por la diseñadora Lorena Velasco Terán. Se parte del supuesto de que Drem es una historieta mexicana en cuyo argumento se ve presente la posmodernidad como dominante cultural, aun cuando conserva rasgos de la narrativa moderna. Objetivo. Analizar la iconografía y gráfica del manga mexicano Drem para identificar los elementos propios de la modernidad y posmodernidad presentes en la narrativa visual y escrita. Método. Análisis de la imagen basado en el paradigma de inferencias indiciales de Carlo Ginzburg, por medio del cual se identificaron detalles en la gráfica de la fuente primaria para después rastrear sus referentes históricos y culturales. Finalmente, se analizan dichos referentes por medio de las propuestas de Jameson y García Canclini. Resultados. La narración retoma elementos del cuento fantástico moderno y del posmoderno, los cuales se entremezclan y separan por momentos. Del cuento fantástico moderno, la narración retoma el sueño y el psicoanálisis para ubicar lo sobrenatural en el interior del sujeto. Del cuento fantástico posmoderno, la

\footnotetext{
${ }^{1}$ Historieta japonesa.
} 


\section{Revista Iberoamericana \\ de las Ciencias Sociales y \\ Humanísticas}

ISSN: $2395-7972$

narración emplea la multiplicidad del yo del sujeto, el fenómeno religioso intercalado con lo psicoanalítico, la ruptura espacial y temporal. Conclusiones. En este manga mexicano la posmodernidad se presenta como dominante cultural en los primeros seis volúmenes; en el último predomina la modernidad. Drem es un producto creado en un contexto en el que el diálogo entre los diferentes productos gráficos de culturas lejanas y distantes se acentúa y da paso a creaciones nuevas donde la fragmentación y las mezclas espaciales-temporales son constantes en narrativas que se traslapan y rompen como reflejo del mundo posmoderno creado por las borrosas fronteras actuales.

Palabras clave: cómic, cuento fantástico, hibridez, religión, sueño.

\section{Abstract}

Introduction. This article discusses the Mexican manga DREM, created and published in Mexico in 2008 by the designer Lorena Velasco Terán. It is assumed that DREM is a Mexican comic strip in whose argument postmodernity is presented as a cultural dominant, even though the features of modern narrative are preserved. Objective. Analyze the iconography and graphics of the Mexican manga DREM, to identify the elements of modernity and postmodernity present in the visual and written narrative. Method Analysis of the image based on the paradigm of inferential inferences of Carlo Ginzburg by means of which, details were identified in the graph of the primary source, and then trace its historical and cultural references. Finally, the references of Jameson and García Canclini are analyzed. Results. We came to the conclusion that the narrative takes elements of the modern and postmodern fantastic story, which are intermingled and separated at times. From the fantastic modern story, the narrative takes up the dream and psychoanalysis to locate supernatural within the subject. From the fantastic postmodern tale, the narrative takes up the multiplicity of the subject's self, the religious phenomenon interspersed with the psychoanalytic, the spatial and temporal rupture. Conclusions In this mexican manga, postmodernity appears as a cultural dominant in the first six volumes; in the last, modernity predominates. DREM is a product created in a context in which the dialogue between the different graphic products of distant and distant cultures is accentuated, and gives way to new creations where fragmentation and spatial / temporal mixtures are constant in overlapping narratives and They break, as a reflection of the postmodern world created by today's blurred borders. 


\section{Revista Iberoamericana \\ de las Ciencias Sociales y \\ Humanísticas}

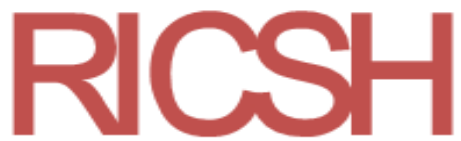

ISSN: $2395-7972$

Keywords: comics, fantasy tale, hybridity, religion, dream.

\section{Resumo}

Introdução Este artigo analisa o mangá mexicano Drem, criado e publicado no México em 2008 pela designer Lorena Velasco Terán. Supõe-se que Drem seja uma história em quadrinhos mexicana cujo argumento é que a pós-modernidade está presente como dominante cultural, embora retenha características da narrativa moderna. Objetivo Analisar a iconografia e gráficos do mangá mexicano Drem para identificar os elementos da modernidade e pós-modernidade presentes na narrativa visual e escrita. Método Análise da imagem baseada no paradigma das inferências inferenciais de Carlo Ginzburg, por meio das quais detalhes foram identificados no gráfico da fonte primária e, em seguida, traçar seus referentes históricos e culturais. Por fim, esses referentes são analisados por meio das propostas de Jameson e García Canclini. Resultados A narrativa toma elementos do conto fantástico moderno e pós-moderno, que são misturados e separados às vezes. A partir da fantástica história moderna, a narrativa retoma o sonho e a psicanálise para localizar o sobrenatural dentro do sujeito. Do fantástico conto pós-moderno, a narrativa utiliza a multiplicidade do eu do sujeito, o fenômeno religioso intercalado com a psicanálise, a ruptura espacial e temporal. Conclusões Nesse mangá mexicano, a pós-modernidade é apresentada como dominante cultural nos primeiros seis volumes; no último, a modernidade predomina. Drem é um produto criado em um contexto no qual o diálogo entre os diferentes produtos gráficos de culturas distantes e distantes é acentuado e dá lugar a novas criações onde a fragmentação e as misturas espaço-temporais são constantes em narrativas que se sobrepõem e se quebram como um reflexo do mundo pós-moderno criado pelas fronteiras borradas de hoje.

Palavras-chave: história em quadrinhos, história fantástica, hibridismo, religião, sonho.

Fecha Recepción: Enero 2019

Fecha Aceptación: Mayo 2019 


\section{Revista Iberoamericana \\ de las Ciencias Sociales y \\ Humanísticas}

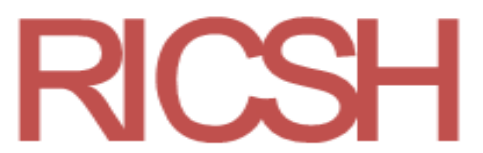

ISSN: $2395-7972$

\section{Introducción}

La introducción del manga japonés a México durante la década de los noventa, como resultado de la implantación del modelo neoliberal, tuvo como resultado no solo el encuentro de los creadores locales con maneras de narrar y dibujar desconocidas hasta entonces, sino el descubrimiento de temas nuevos, los cuales fueron retomados por los historietistas locales para adoptar sus historias. De las investigaciones que se han realizado en México sobre el tema del manga, se pueden encontrar tres grandes vertientes: las publicaciones que analizan la gráfica japonesa anterior al manga — como el Ukiyo-e y el Shunga, en este rubro destaca Amaury García (2005, 2009, 2011)_, además, están las publicaciones de carácter monográfico que tratan el manga de manera general, como las de Brigitte (2008) y Schodt (1983). Finalmente, se encontraron publicaciones académicas que examinan desde un enfoque teórico algún manga o anime, como los textos de Papalini (2006) y Poloniato (2008).

Esta revisión preliminar deja en claro que se han concretado pocos intentos por estudiar la manera en la que el manga se ha adaptado al introducirse a México (Cobos, 2010), país que contaba con una amplia tradición gráfica y de elaboración de historietas. De hecho, tampoco se ha examinado la forma en que se han adoptado temas como la estética posmoderna a las narraciones de la historieta mexicana, creadas bajo la influencia del manga japonés. Esto genera la inquietud por analizar, como un estudio de caso, la iconografía y gráfica de un manga mexicano con el fin de identificar los elementos propios de la modernidad y la posmodernidad presentes en su narrativa visual y escrita.

En este artículo, por ende, se profundiza en el manga mexicano Drem, creado y publicado, de manera independiente, en México en 2008, por la diseñadora Lorena Velasco Terán. Para ello, se parte de que Drem es una historieta mexicana, con características de manga, en cuyo argumento aparece latente la posmodernidad como dominante cultural, aun cuando conserva rasgos de la narrativa moderna. Esta afirmación se sustenta en el hecho de que la narración retoma elementos del cuento fantástico moderno y posmoderno, los cuales se entremezclan y se separan por momentos. Del cuento fantástico moderno, la narración retoma el sueño y el psicoanálisis para ubicar lo sobrenatural en el interior del sujeto. Del cuento fantástico posmoderno, la narración emplea la multiplicidad del yo del sujeto, el fenómeno religioso intercalado con lo psicoanalítico, así como la ruptura espacial y temporal. 


\section{Revista Iberoamericana \\ de las Ciencias Sociales y \\ Humanísticas}

ISSN: 2395 - 7972

Finalmente, la posmodernidad se trata como dominante cultural en los primeros seis volúmenes, mientras que en el último sobresale la modernidad.

Drem se publicó en un contexto en el que las convenciones de cómics habían empezado a cobrar auge en México. La versión que se analiza en estas páginas salió a la venta en 2008, aunque vale destacar que esta historia ya había sido publicada de manera parcial entre 2003 y 2004 bajo el sello del Estudio Luciérnaga. La versión de 2008 se publicó bajo el sello del Estudio Syanne ${ }^{2}$, con formato tamaño carta, portadas en papel couché, a color e interiores en bond en blanco y negro. La historia está dividida en siete volúmenes: los primeros seis tienen 40 páginas y el último de 67. Esta historieta se comercializó en convenciones de cómics y en la tienda de Estudio Syanne, ubicada en la Frikiplaza, Ciudad de México, Lázaro Cárdenas 9, Colonia Centro, local 34, primer piso.

El personaje principal de Drem se llama Neve, una estudiante de preparatoria que, luego de sufrir la pérdida de su madre, crea un sueño para evadir la realidad. Dentro de la fantasía, la madre de Neve está viva y ella se encuentra en un ambiente escolar estable que ocasionalmente se ve interrumpido por pesadillas y fantasías. La narración finaliza cuando la protagonista logra despertar y aceptar los hechos.

Este manga es una zaga desarrollada en siete episodios divididos en la misma cantidad de volúmenes. En el primer episodio se dan a conocer los personajes y la situación que viven; aquí es determinante la primera escena, ya que resulta decisiva para comprender el sentido de la historia, revelado en el último volumen. Luego, entre el segundo y sexto volumen se desarrolla la fantasía de la protagonista, en la cual surgen situaciones cotidianas vividas por adolescentes aparentemente preparatorianos. El último tomo revela la situación real de la fantasía que se lee a lo largo de los volúmenes anteriores y concluye con una resolución al conflicto de la protagonista.

\footnotetext{
${ }^{2}$ El Estudio Syanne se fundó en 2008; sus integrantes son Mauricio Alberto Sánchez Serrano y la propia Lorena Velásco Terán.
} 


\section{Revista Iberoamericana \\ de las Ciencias Sociales y \\ Humanísticas}

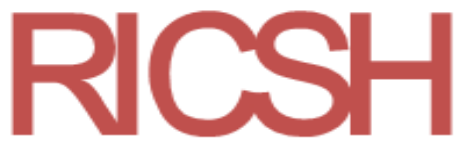

ISSN: $2395-7972$

\section{Método}

Para llevar a cabo este análisis se usaron como fuente primaria los siete fascículos de Drem, así como las entrevistas con la autora. Las fuentes secundarias están constituidas por la bibliografía y el material audiovisual consultado. Asimismo, se tomaron tres imágenes de Drem, las cuales se consideró que agrupaban en la historia y gráfica del manga los conceptos principales de posmodernidad e hibridación. Luego se realizó un análisis basado en la identificación de detalles presentes en la gráfica e historia, a partir de los cuales se rastrearon los principales referentes iconográficos e históricos que después sirvieron para explicar cómo se integraban en el relato. En este sentido, se realizó una interpretación de la imagen — la cual funge como fuente principal, y no como ilustración-, por lo que los referentes se rastrearon desde su contexto, donde significan y se "proyectan en el imaginario, que tiene que ver con un espacio de significación y afección acotado y fraccionado en ámbitos determinados" (Larrañaga, 2017, p. 8 ).

El examen presentado en estas páginas se basa en el paradigma de inferencias indiciales propuesto por Ginzburg (1999), quien propone un método inductivo de análisis basado en la identificación de detalles marginales, los cuales permiten el acceso a procesos simbólicos y culturales más amplios, propios del contexto sociohistórico en el que la fuente se creó. En otras palabras, es un "método interpretativo basado en lo secundario, en los datos marginales considerados reveladores. Así, los detalles que habitualmente se consideran poco importantes, o sencillamente triviales, 'bajos', proporcionan la clave para tener acceso a las más elevadas realizaciones del espíritu humano" (1999, p. 143).

Asimismo, se tomaron en cuenta los siguientes teóricos de la posmodernidad y la hibridez: en primer lugar, Fredrick Jameson, para quien la posmodernidad es la estética del capitalismo tardío — este último es la forma más pura de capitalismo (2005). Esta propuesta reviste de especial interés porque Jameson no plantea la posmodernidad como un periodo específico, sino como una dominante cultural. Al respecto, señala:

[Los] rasgos que en un período o sistema anterior estaban subordinados ahora pasan a ser dominantes, y otros que habían sido dominantes se convierten en secundarios. En este sentido, todo lo que hemos descripto aquí puede encontrarse en períodos anteriores y muy en particular en el modernismo propiamente dicho (1998, p. 35). 


\section{Revista Iberoamericana \\ de las Ciencias Sociales y \\ Humanísticas}

ISSN: 2395 - 7972

Lo anterior permite entender que los rasgos del periodo posmoderno pueden coexistir con las características de la posmodernidad, hecho que ocurre en Drem, donde los diversos elementos constitutivos del cuento fantástico moderno se alternan con los del posmoderno hasta que en el último volumen la modernidad se vuelve la dominante cultural.

Además de Jameson, en este trabajo se retomó la noción de posmodernidad que propone García Canclini, quien la define como el producto de la mezcla entre la tradición y la modernidad: "La posmodernidad no es una etapa o tendencia que reemplazaría al mundo moderno, sino una manera de problematizar los vínculos equívocos que este armó con las tradiciones que quiso excluir o superar para constituirse" (2009, p. 23). Al igual que Jameson, para Canclini la posmodernidad no es un periodo, sino que se caracteriza por la transposición de elementos provenientes de la tradición y la modernidad. En este caso, ambas nociones de posmodernidad son compatibles, ya que la visión de posmodernidad de Jameson, al tomarse como dominante cultural, admite la existencia de elementos modernos y tradicionales dentro de ella.

Uno de los rasgos más característicos de la posmodernidad es la hibridez y la mezcla de elementos procedentes de diversos orígenes, que se integran en un nuevo contexto y, por lo tanto, en un nuevo producto. En este sentido, se trabajó la noción de hibridez de García Canclini, quien la concibe como "procesos socioculturales en los que estructuras o prácticas discretas, que existían en forma separada, se combinan para generar nuevas estructuras, objetos y prácticas" (2009, p. 2). Esta postura en torno a la hibridez resulta esencial porque se reconoce que los productos generados de esta manera pueden contener un desgarramiento y elementos que no llegan a fusionarse (2009).

\section{Resultados}

Drem es una historieta con características de manga, con el que comparte un tipo de dibujo similar en blanco y negro, así como otras convenciones acerca de las cuales no se profundizó en este artículo, pues ya fueron tratadas en otra publicación (Castelli, 2017). Aun así, conviene resaltar que de la historieta mexicana mantiene el formato tamaño carta, las portadas a color, los nombres occidentales de los personajes y el entorno en el que se desarrolla la historia. Por sus características que retoman convencionalismos de ambas 


\section{Revista Iberoamericana \\ de las Ciencias Sociales y \\ Humanísticas}

ISSN: 2395 - 7972

culturas, esta historieta es un producto híbrido no solo en el contenido de la historia, sino en su propio formato.

La historia completa Drem está constituida por cuatro secuencias, cada una con su respectiva matriz actancial. De la secuencia uno a la tres las matrices se desdoblan en el nivel del ser y del parecer, pues constantemente se juega con la idea de Neve conquistando y manteniendo el amor de su amigo Noah, para lo cual lucha al inicio con su amiga Leely y después con Ari, la amiga de Noah. De esta manera el personaje procura mantener un sueño agradable con lo cual puede seguir evadiendo la pérdida de su ser querido.

La última secuencia solo se enfoca en el nivel del ser, pues el objeto de Neve es superar la muerte de su madre: ella es su destinador y su destinatario. Para lograrlo cuenta con la ayuda de su padre y sus amigos; en este proceso su principal oponente es ella misma, aunque en menor medida, ya que ha superado el shock inicial, por lo que está dispuesta a despedirse de su madre de manera simbólica.

Pese a que la anterior descripción muestra una historia que de manera superficial parece completamente lineal y de corte psicológico, en algunas fases se observan rupturas y desdoblamientos espaciales, temporales y físicos en relación con los personajes. Tres imágenes condensan los principales resultados de los detalles gráficos y temáticos.

Por ejemplo, en la figura número 1 (extraída del volumen uno) se observa cuando Neve pasa de su realidad al sueño sin que el lector se dé cuenta; la imagen ocupa toda la página y en ella se aprecia a la protagonista sentada en el agua y dos cortinas que hondean y la rodean mientras ella dice: “Aquí me siento completa” (Velasco, 2008). 


\section{Revista Iberoamericana \\ de las Ciencias Sociales y \\ Humanísticas}

ISSN: $2395-7972$

Figura 1. Primera imagen analizada de Drem

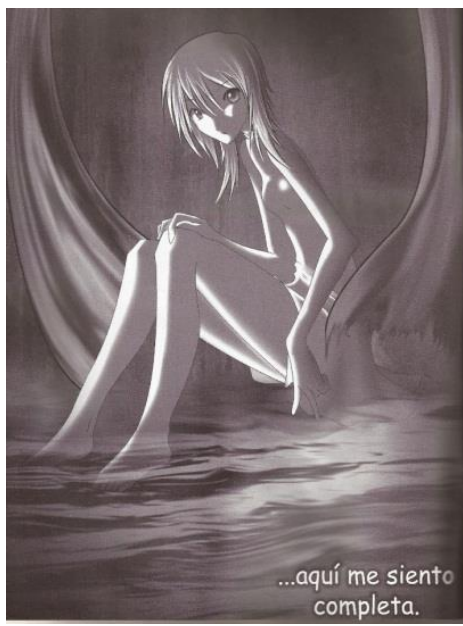

Fuente: Velasco Terán (2008)

En la figura 1 el elemento que se destaca es un cambio de dimensión, pues se trata de un sueño dentro del sueño principal, lo que muestra la existencia, en el relato, de especies de dimensiones anidadas una dentro de la otra.

En la figura 2, ubicada en el volumen número siete, se observa otro desdoblamiento, en este caso del personaje principal, quien a lo largo del relato se divide en varios yoes. Esta imagen también ocupa toda la página y presenta dos viñetas superpuestas a la imagen principal, en la parte superior de la hoja. En la primera se observa a Neve en médium close up; ella dice: ¿Quién eres?; a la derecha, en otra viñeta, se observa el perfil de una mujer de cabello lacio que pregunta: ¿No lo recuerdas? Debajo de estas viñetas, en el centro, se presenta a la última mujer de cuerpo completo, desnuda y cubierta únicamente con listones; la pared se abre y esta mujer aparece flotando en un fondo oscuro, con un pez a su derecha. Ella extiende la mano a Neve y le dice: Ven a mí y recordaremos lo fascinante y maravilloso que es este lugar. Esta imagen condensa la tendencia de la historia a jugar con desdoblamientos espaciales y del sujeto con motivo del tema psicológico y posmoderno, como se explicará más adelante. 


\section{Revista Iberoamericana \\ de las Ciencias Sociales y \\ Humanísticas}

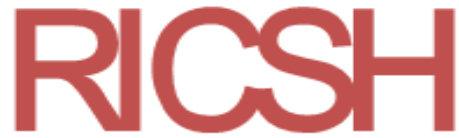

ISSN: $2395-7972$

Figura 2. Segunda imagen analizada de Drem

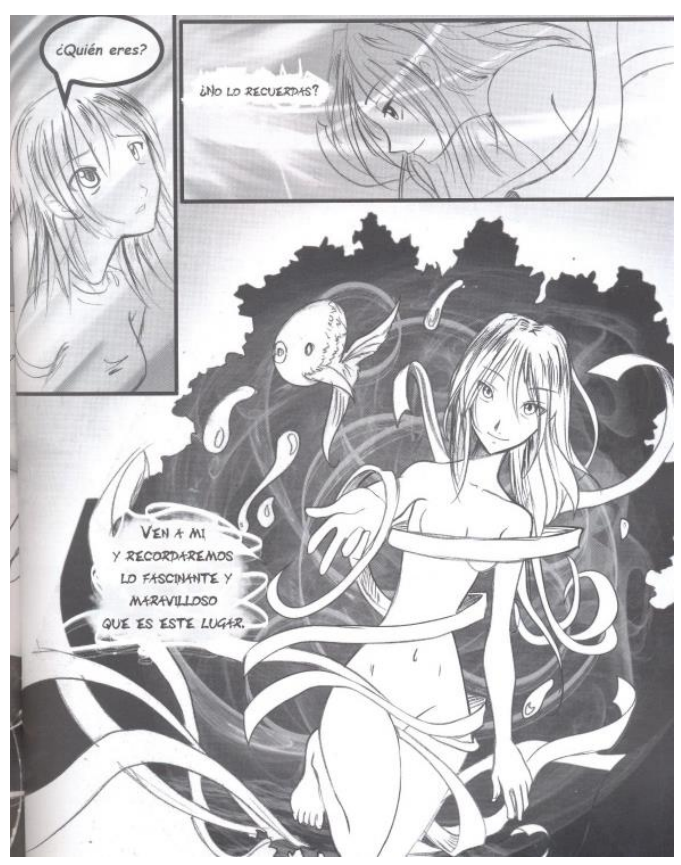

Fuente: Velasco Terán (2008)

En la tercera imagen analizada (figura 3), ubicada también en el volumen siete, se representa a Leely, la amiga de Neve, en primer plano, con un fondo oscuro, los brazos en cruz y un par de alas blancas extendidas; ella dice: Neve... mírame sin miedo, soy tu guardián. Esta última imagen resulta crucial porque introduce una dimensión religiosa a una historia que hasta ese momento jugaba únicamente con los factores psicológicos, lo cual hibrida motivos y hace más compleja la historia. 


\section{Revista Iberoamericana \\ de las Ciencias Sociales y \\ Humanísticas}

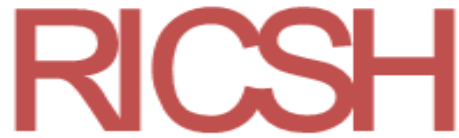

ISSN: $2395-7972$

Figura 3. Tercera imagen analizada de Drem

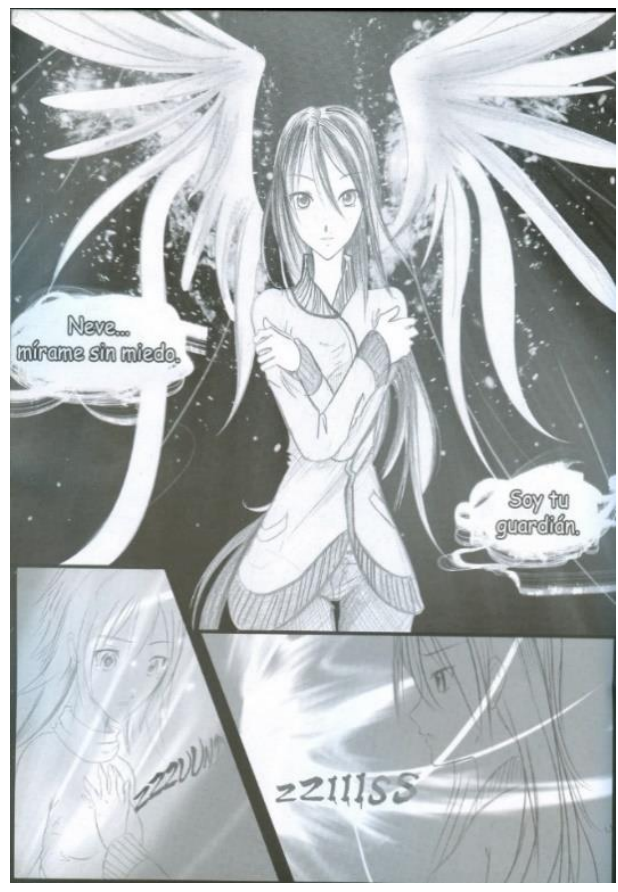

Fuente: Velasco Terán (2008)

\section{Discusión}

El lector debe recordar que se partió del supuesto de que Drem es una historieta mexicana en cuyo argumento se ve presente la posmodernidad como dominante cultural, aun cuando conserva rasgos de la narrativa moderna. Por este motivo, se plantea que esta historieta retoma elementos del cuento fantástico moderno en su narración, ya que emplea elementos temáticos como el sueño y el psicoanálisis para ubicar lo sobrenatural en el interior del sujeto.

En cuanto a la posmodernidad, esta emerge en la multiplicidad del yo del sujeto, el fenómeno religioso intercalado con lo psicoanalítico, la ruptura espacial y temporal. Además, la posmodernidad es la dominante cultural en los primeros seis volúmenes, mientras que en el último predomina la modernidad, pues se revela que todos los efectos disparatados de la narrativa corresponden a un sueño del sujeto. 


\section{Revista Iberoamericana \\ de las Ciencias Sociales y \\ Humanísticas}

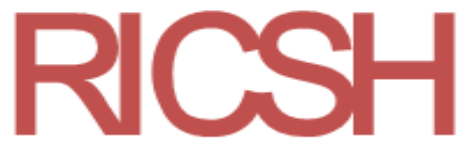

ISSN: $2395-7972$

\section{Drem: entre la modernidad y la posmodernidad}

Dentro de la historia son pocas las informaciones que ayudan a situarla temporalmente, pues no se mencionan hechos que pudieran relacionarse con situaciones contextuales por las que pasaba México en el momento de su creación. De hecho, la temática solo se desarrolla en la mente de la protagonista, donde suceden toda una serie de fenómenos extraños y simbólicos. Es decir, los motivos psicológicos son el tema principal, sobre todo en la parte del sueño, la cual solo se presenta como tal en el último volumen de la colección.

Ahora bien, según Freud, las brechas del sueño se podían atribuir a una compleja interacción entre las instancias metapsicológicas y tópicos:

En principio el Yo desea dormir, y por lo tanto es preciso soñar: en efecto, cuando hay un deseo que surge del inconsciente, el sueño se ofrece como la única solución que pueda saciar y a la vez evitar cualquier despertar incipiente (Metz, 1977, p. 105).

Así, el yo de Neve desea dormir y evadir la realidad para soportar el dolor de su pérdida; en consecuencia, sueña su sueño, el cual generalmente está colmado de experiencias positivas para intentar saciar su deseo inconsciente de evadir la pérdida y no despertar. De hecho, cuando el sueño se empieza a tornar en pesadilla, hay otro sueño dentro del sueño que invita a Neve a dejarse llevar y morir.

Pero la única parte inconsciente del Yo, la instancia refutadora (la defensa), de acuerdo con el Súper Yo que la inspira, permanece en un constante semi despertar, puesto que lo rechazado, y más comúnmente lo prohibido, contra quienes ella está encargada precisamente de mantener la defensa, también permanecen despiertos y activos, o al menos susceptibles de activación durante el mismo sueño (Metz, 1977, p. 105).

Neve se desdobla en varias partes en su sueño: como quiere permanecer en él y es, en parte, inconsciente de que lo que vive no es real, la instancia refutadora de su yo toma tres formas: la suya propia, que vigila y se asegura de que nada la despierte; la que evita a su madre, que está viva en el sueño, y la que le cierra las puertas para que con su presencia no reviva los recuerdos: "La vigilancia de la parte del yo, que permite que la otra siga durmiendo, suele revestir la forma de censura, ésta como sabemos, influye incluso en nuestros sueños 


\section{Revista Iberoamericana \\ de las Ciencias Sociales y \\ Humanísticas}

ISSN: 2395 - 7972

más plenos" (Metz, 1977, p.105). Esta parte de ese yo ha tomado su propia forma y se asegura de que nada la despierte.

Pero hay otra forma de esta parte del yo de Neve presente en el sueño que adopta la forma de una misteriosa mujer, la cual sale de las paredes de la habitación y la amenaza de muerte (ver figura 2). Esta otra forma es el extremo, la cual no quiere que Neve despierte, ni piense, ni analice, por lo que la seduce con imágenes de agua, oscuridad y una falsa tranquilidad que, sin embargo, hace que el sueño se torne en pesadilla.

No obstante, puede ocurrir que esta instancia de auto observación y de auto vigilancia se vea obligada a interrumpir el dormir a diversas escalas, dado que los dos efectos contrarios proceden empero de la misma misión de defensa, que ahora, sin embargo, se ejerce en condiciones distintas. Un determinado sueño asusta demasiado; la censura, en la primera fase, no ha logrado edulcorar lo suficiente su contenido, de manera que intervendrá nuevamente para detenerlo, y de paso para detener el dormir (Metz, 1977, p. 105).

Este último desdoblamiento de Neve en el sueño cumple la función de instancia de autoobservación y toma la forma de su amiga Leely. Por un lado, la propia Neve se defiende del despertar cuando los recuerdos amenazan con despertarla; así, la defensa torna el sueño en situaciones positivas y el noviazgo de Neve con Noah se materializa (primer desdoblamiento). No obstante, hay otra parte del yo de Neve que no quiere despertar jamás, por lo que la seduce, la llama a través de las paredes y vuelve el sueño en pesadilla (segundo desdoblamiento: mujer que sale de las paredes).

Finalmente, cuando en el sueño Noah es asesinado por la mujer que sale de las paredes, la instancia de autoobservación Leely (tercer desdoblamiento de Neve) acude a ella para hacerle saber lo que está soñando y para despertarla de una vez, lo cual ocurre. El manejo del sueño dentro de Drem asume las formas descritas por Metz acerca del psicoanálisis: la idea de un deseo inconsciente y la vigilancia de la parte consciente del yo; además, se pueden ver simbolismos recurrentes como el agua y la oscuridad.

Según Cooper (2004), las aguas, que abundan en ese lugar de oscuridad a donde Neve suele viajar en su propio sueño (ver figura 1), "son símbolo de la Gran Madre y están asociadas al nacimiento, el principio femenino, útero universal, la prima materia, las aguas 


\section{Revista Iberoamericana \\ de las Ciencias Sociales y \\ Humanísticas}

ISSN: $2395-7972$

de fertilidad y del frescor" (p. 11). Esto, aunado a las sombras de la noche ${ }^{3}$, viene a acentuar el hecho de que el lugar que Neve sueña, en su sueño, le remite a la seguridad de su madre: un lugar seguro en el que se siente tranquila y en el que sin embargo — por el simbolismo de la noche y la oscuridad — también puede sumirla en la locura, el caos, la desintegración y la muerte.

La abundancia de estos elementos psicológicos y oníricos son los que le dan a Drem características del cuento fantástico moderno, las cuales están presentes a lo largo de toda la historia acentuándose en el volumen número siete. En otras palabras, desde el inicio se observan situaciones sobrenaturales que irrumpen en el entorno cotidiano de la protagonista, característica principal de lo fantástico en el relato, ya que "la mayor parte de las teorías sobre lo fantástico confluyen en el hecho de que existen dos elementos que al principio se oponen: la cotidianeidad y el elemento extraño que viene a romper la normalidad del orden establecido" (Nieto, 2015, pp. 59-60).

Por tanto, los misteriosos viajes de Neve a una realidad alterna de oscuridad y agua donde Leely la visita, así como la aparición de la extraña mujer que la incita a desaparecer y a olvidar son las mencionadas situaciones sobrenaturales que aparecen en su cotidianeidad y la asustan (figura 4).

\footnotetext{
${ }^{3}$ Del mismo modo que la oscuridad, la noche se refiere a las tinieblas precosmogónicas y prenatales que anteceden al renacimiento o reiniciación, aunque también significa caos, muerte, locura, desintegración, regreso al estado fetal del mundo (Cooper, 2004, p. 124).
} 


\section{Revista Iberoamericana \\ de las Ciencias Sociales y \\ Humanísticas}

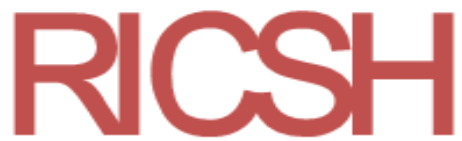

ISSN: $2395-7972$

Figura 4. La realidad alterna que visita Neve en sueños

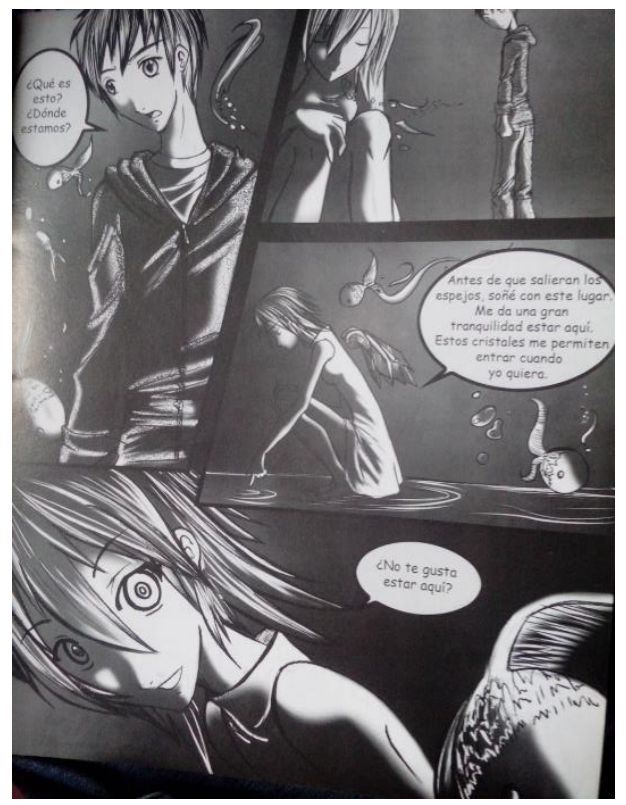

Fuente: Velasco Terán (2008)

De esta manera, cuando el lector tiene su primer acercamiento a Drem, el factor fantástico pareciera más orientado a lo clásico, porque aparentemente todos esos elementos extraños y sobrenaturales son externos a Neve, los cuales la seducen y acechan. En este sentido, Nieto (2015), afirma que

La otredad en el esquema del paradigma de lo fantástico clásico puede ubicarse fuera del hombre, como una entidad externa. Satán o los ángeles, todas esas figuras sobrenaturales o mágicas se colocan fuera de lo meramente humano, como propias de una dimensión diferente a la nuestra (p. 65).

Efectivamente, en Drem la mujer y el lugar oscuro están en una dimensión diferente a la de Neve debido a que la historia maneja tres escenarios: la realidad de Neve, su sueño anclado en un mundo cotidiano y el sueño que tiene dentro del sueño, en donde viaja al entorno húmedo y oscuro. Así, se puede hablar de la existencia de lo fantástico clásico dentro de lo fantástico moderno, otra de las características de la posmodernidad en las que se ahondará más adelante.

Los elementos de lo fantástico moderno se hacen dominantes y cobran todo el sentido cuando el lector se da cuenta, en el último volumen, de que todo lo que ocurre desde el principio es un sueño creado por Neve para evadir la muerte de su madre; entonces, toman 


\section{Revista Iberoamericana \\ de las Ciencias Sociales y \\ Humanísticas}

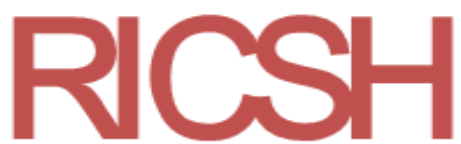

ISSN: 2395 - 7972

preeminencia todos los elementos psicológicos anteriormente descritos respecto al sueño y el psicoanálisis. Al respecto, Nieto (2015) precisa:

La otredad, que hasta el siglo XIX fue por completo externa, es sustituida paulatinamente por temores 'internos', esto a partir del psicoanálisis, con base en el cual la literatura fantástica moderna ubica a todos los fantasmas dentro de los seres humanos. En el ámbito textual, los oscuros deseos, frustraciones, impulsos, terrores y temores ya no son transcritos como elementos extraños, sino que están diluidos dentro del texto mismo, como alegoría del lugar que guardan dentro del ser humano (p. 134).

Así, todo aquello que en un principio pareciera fantástico externo es en realidad interno, obra de un sueño en la mente de Neve, quien busca evadir con ello la muerte de su madre; de esta manera Drem cumple con una de las características específicas del cuento fantástico moderno: ubicar la otredad en el interior del hombre; pero eso insólito, además, se encuentra oculto, porque la otredad se "oculta textualmente dentro de la narración hasta que emerge desde el universo del protagonista o de algún personaje específico" (Nieto, 2015, p. 139).

En este manga mexicano, lo insólito va surgiendo poco a poco, develándose por capas, de la mano de Leely o la propia Neve (no se debe olvidar que, en ambos casos, se trata de desdoblamientos del yo de Neve). Paradójicamente, a medida que lo insólito se muestra, se va tornando en lo siniestro, lo cual es "una suerte de material abyecto que ha estado oculto y se manifiesta al emerger" (Nieto, 2015, p. 143). Lo siniestro es otra particularidad del cuento fantástico moderno que en Drem se observa principalmente por un par de alas de cristal que brotan de la espalda de Neve a mitad de la historia; además de lo anterior, lo siniestro surge en el segundo desdoblamiento del yo de Neve: la mujer que en el último volumen irrumpe de las paredes de la habitación de la protagonista y la incita a desaparecer (figura 5). Tanto la mujer como Leely, desde el aspecto psicológico del sueño, son desdoblamientos del yo de Neve, pero la primera se vincula particularmente a lo siniestro por aparecer como un ente que quiere acabar con la vida de Neve y surgir a través de las paredes en el tomo siete. 


\section{Revista Iberoamericana \\ de las Ciencias Sociales y \\ Humanísticas}

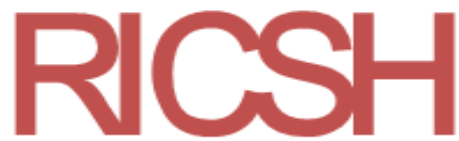

ISSN: $2395-7972$

Figura 5. Desdoblamiento del Yo de Neve. La muerte

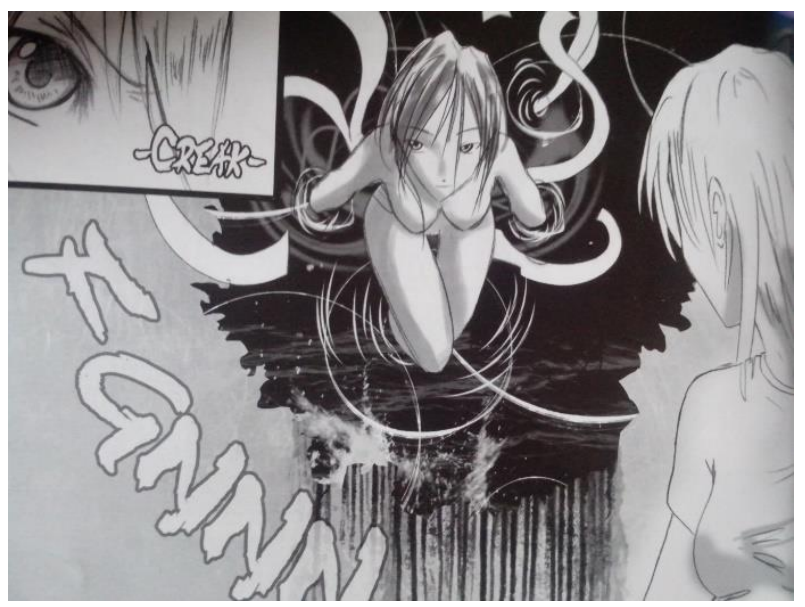

Fuente: Velasco Terán (2008)

El psicoanálisis de Freud considera la presencia de dobles como siniestro (aunque no tenga las mismas características de Neve, son sus dobles) debido a su función como enunciadores de la muerte (Lobo, 2010), elemento que se presenta en Drem, ya que aunque todo se trata de un sueño, Neve está en coma al borde de la muerte.

Es necesario destacar, por tanto, que en la última parte del sueño, la historia parece pasar del factor psicológico al religioso, ya que justo antes de que Neve despierte se da una pugna entre Leely — quien se presenta como guardián de Neve, ya que tiene la función de mostrarle a ella que "del otro lado existe otro mundo" (Nieto, 2015, pp. 146-147) - y el emisario del mundo del más allá que surge de las paredes para llevarse a la protagonista (este carácter híbrido de psicoanálisis y religión se profundizará más adelante cuando se hable de las características del cuento fantástico posmoderno).

Por otro lado, Drem presenta factores que lo identifican con la posmodernidad; por ejemplo, su apariencia gráfica, su estructura narrativa y las características del cuento fantástico moderno y clásico. Muñoz Rangel (2010) plantea dos aspectos desde los cuales se pueden ubicar características propias de este tipo de relatos, es decir, la naturaleza del mundo y la naturaleza del yo. En el primer caso, están presentes aquellos relatos en donde hay teorías del universo o una preocupación de la naturaleza del universo, además de desórdenes en la continuidad espacial-temporal, paso a otros planos de realidad, mundos futuribles y lugares imaginados. En cuanto a la naturaleza del yo, abarca el tema de la identidad y la disolución del yo, el tema del doble, la reencarnación y los fantasmas desde el otro lado. 


\section{Revista Iberoamericana \\ de las Ciencias Sociales y \\ Humanísticas}

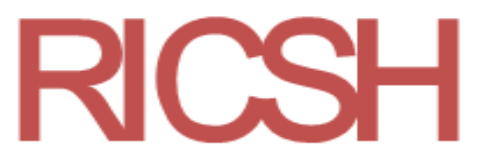

ISSN: 2395 - 7972

Ahora bien, aunque es cierto que en Drem no se manifiestan todos los factores señalados en los dos aspectos referidos, sí tiene un gran número de ellos. Por ejemplo, en cuanto a la naturaleza del mundo, se observan los desórdenes en la continuidad espacial y temporal, ya que desde el primer volumen hay una transición en el espacio y tiempo donde se desarrolla el relato sin que el espectador ni el sujeto de la historia lo noten; de hecho, la narración se desarrolla en tres espacios diferentes: la realidad en la que vive Neve, el sueño de ella, y el mundo de oscuridad y agua al que viaja a través de las paredes y sueños, el cual, al parecer, es el más allá (esto último permite apreciar otros planos de la realidad).

Igualmente, se localizan los lugares imaginados, ya que al desarrollarse la mayor parte de la historia en un sueño, esa realidad ideal y perfecta en principio, pero monstruosa después, surge solo de la mente de Neve. Aunado a esto, la lucha que se da entre el guardián de Neve, encarnado por Leely (tercer desdoblamiento del yo de Neve) en el sueño y la mujer que invita a Neve a morir (segundo desdoblamiento del yo de Neve) revela la existencia de un plano religioso en el relato, es decir, un mundo de los muertos y un paraíso.

En relación con la naturaleza del yo de Neve, en Drem se aprecia su identidad y disolución, ya que la trama gira en torno a un problema psicológico, lo que detona toda una serie de disoluciones del yo dentro del sueño, de manera que, como dice Muñoz Rangel, (2010), "el individuo está perdido en ese nuevo laberinto inextricable que es ahora la realidad" (p. 10). Además de lo anterior, este mismo autor agrega:

La personalidad múltiple, los trastornos alucinatorios, las alteraciones del sueño, de la memoria o de la percepción y todo tipo de perturbaciones han sido siempre una tierra fecunda para la literatura fantástica. Y ahora todos estos males hunden sus raíces en los abismos del yo (2010, pp. 10-11).

Relacionado con lo anterior, y como ya se ha explicado constantemente, se da la presencia de dobles y fantasmas, aunque al final todo se explique debido al sueño de Neve. Además, Drem cumple con otro elemento relacionado con el cuento fantástico posmoderno, el cual forma parte de las características asignadas por Nieto (2015) a este tipo de relatos: "El fantástico posmoderno relativiza los estatutos de realidad sobrenatural para hacerlos itinerantes dentro de la estructura textual” (p. 234). Este factor se asocia con los desórdenes espacio-temporales mencionados en renglones anteriores, ya que al jugar con la espacialidad y temporalidad, el propio fenómeno sobrenatural pasa de un plano a otro dentro del sueño. 


\section{Revista Iberoamericana \\ de las Ciencias Sociales y \\ Humanísticas}

ISSN: 2395 - 7972

Para entender la manera en la que los anteriores elementos explicados se presentan en Drem, es necesario volver a Calabrese (1999), quien usa el término barroco para referirse no a un periodo específico de la historia de la cultura, sino a una cualidad en los objetos. Desde su perspectiva, puede haber algo de barroco en cualquier época de la civilización; de hecho, plantea que la sociedad pasa por periodos en donde la cualidad clásica predomina sin que se extinga el barroco, y viceversa. Según esta interpretación, la época actual es un periodo donde predomina el barroco, ya que se le pueden asignar una serie de cualidades estéticas específicas para identificarlo: la repetición, el límite y el exceso, el detalle y el fragmento, la inestabilidad y la metamorfosis, el desorden y el caos, el nudo y el laberinto, la complejidad y la disipación.

Ahora bien, vale acotar que si bien Calabrese se desvincula en primer término de la posmodernidad, en el presente trabajo se utilizó la propuesta de la era neobarroca como parte del fenómeno posmoderno debido a que todas las características que le asigna el referido autor a la mencionada era neobarroca corresponden a la posmodernidad; en relación con lo anterior, Bolívar Echeverría (2000) menciona:

El concepto de 'lo barroco', actualizado por el prefijo 'neo', aparece como uno de los principales instrumentos para pensar en qué consiste ese estar 'después', en 'discontinuidad' o 'más allá' de la modernidad (...). En medio de esta crisis de la modernidad, y más como un refugiarse en alternativas de la vida reprimidas y desechadas por ésta, aparece una cierta práctica de las posmodernidad en la que 'algo así como un paradigma barroco se reivindica y se abre lugar'. Se trata de un comportamiento en el que se reaparece aquella 'constante formal', 'aquel gusto por lo inestable, lo multidimensional, lo mutante', que Omar Calabrese, siguiendo el refinado método de su formalismo riguroso, ha investigado sistemáticamente en la cultura contemporánea (p. 14).

Todos los aspectos del cuento fantástico que se enumeraron hasta aquí y que se ven presentes en Drem aparecen como fragmentos, es decir, "a diferencia del detalle, el fragmento, aun perteneciendo a un entero precedente no contempla su presencia para ser definido; más bien: el entero está in absentia" (Calabrese, 1999, p. 89). Esto significa que son elementos rotos, separados de su contexto original y reinsertos en un nuevo texto que en este caso es la historia de Drem. 


\section{Revista Iberoamericana de las Ciencias Sociales y Humanísticas}

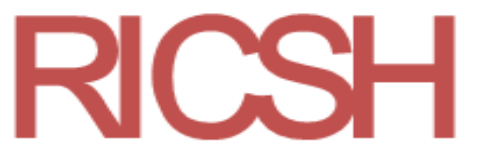

ISSN: 2395 - 7972

Lo anterior permite que dentro de la historieta se pase de cuento fantástico clásico a posmoderno y de lo posmoderno a lo moderno. Tal situación es comprensible si se considera que lo que se lee a lo largo del relato es un sueño y los elementos que lo componen se presentan como pedazos de la realidad; es decir, "el contenido de los elementos oníricos, procede de diversas vivencias del sujeto, tomadas de manera azarosa" (Freud, 2013, p. 30) por el inconsciente. Así, se observa en primera instancia el factor sobrenatural como algo externo al individuo para después notar que todo es un sueño; finalmente, cuando se cree que todo está explicado aparece en escena el factor religioso que flota e impregna la historia, especialmente en el último volumen (ver figura 3).

Aunque pareciera que los mencionados elementos se encuentran dentro de una historia que presenta continuidad en cuanto a su narrativa, es necesario enfatizar que por lo menos el factor sobrenatural, sus matices, las rupturas espaciales (en especial dentro del sueño), así como el factor religioso aparecen de manera espontánea, nadando dentro de la narrativa, lo que nos lleva a la esquizofrenia posmoderna compuesta de piezas procedentes de diversos orígenes. Ejemplo de lo anterior es el juego que se da entre los diversos planos de realidad que se manejan en la obra, los cuales aunque en un principio se confunden y aparentan ser uno solo (sobre todo el sueño y la realidad, al invadir uno al otro de manera subsecuente), se presentan de manera fragmentaria como una serie de "presentes puros sin conexión de tiempo" (Jameson, 2005, p. 110).

La desfragmentación del yo que vive Neve dentro del sueño también parece como un factor de la posmodernidad, como se ha observado en líneas anteriores; se trata de un proceso que ocurre como consecuencia lógica del sueño en el que se desarrolla la historia, pero, por lo mismo, los otros yoes de Neve no aparecen como un doble idéntico, sino que son reconstrucciones de las personas a las que quiere, aprecia o de lo que teme. Además de su desfragmentación del yo en diversos actantes, también se muestra una ruptura en su cuerpo.

Este cuerpo fragmentado, término que he hecho también aceptar en nuestro sistema de referencias teóricas, se muestra regularmente en los sueños, cuando la moción del análisis toca cierto nivel de desintegración agresiva del individuo. Aparece entonces bajo la forma de miembros desunidos y de esos órganos figurados en exoscopia, que adquieren alas y armas para las persecuciones intestinas, los cuales fijó para siempre por la pintura el visionario Jerónimo Bosco, en su ascensión durante el siglo decimoquinto al 


\section{Revista Iberoamericana \\ de las Ciencias Sociales y \\ Humanísticas}

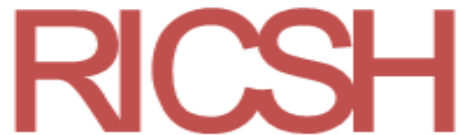

ISSN: $2395-7972$

cénit imaginario del hombre moderno. Pero esa forma se muestra tangible en el plano orgánico mismo, en las líneas de fragilización que definen la anatomía fantasiosa, manifiesta en los síntomas de escisión esquizoide o de espasmo, de la histeria (Lacan, 2009, p. 103).

Lo anterior es evidente por la forma en la que a partir del volumen dos surgen de la espalda de Neve un par de alas de cristal, las cuales la hieren y le dan la facultad de viajar de su sueño al otro sueño de oscuridad y agua, donde un tiempo se siente segura, espacio que al parecer es el mundo de los muertos. Las mencionadas alas de cristal son espejos y no se debe olvidar que estos últimos se identifican con las puertas hacia la muerte (Domínguez, 2002). Este último factor lleva al siguiente punto a desarrollar: el aspecto religioso que se da dentro de la narrativa (figura 6).

Figura 6. Alas de cristal y las puertas de la muerte

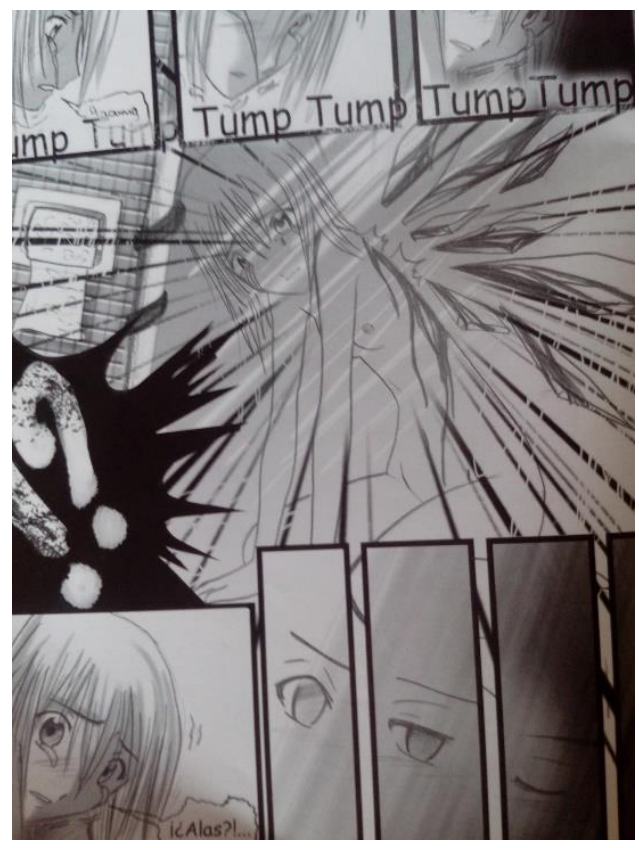

Fuente: Velasco Terán (2008)

Pese a que la historia se desarrolla y se explica primordialmente desde el psicoanálisis, en el último volumen aparece dentro de la historia un fenómeno que resalta por su contradicción con lo psicológico: la religión, la cual se manifiesta en varios aspectos, como la representación de Leely (guardián de Neve), la mujer que surge de las paredes como 


\section{Revista Iberoamericana \\ de las Ciencias Sociales y \\ Humanísticas}

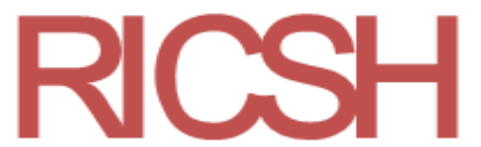

ISSN: 2395 - 7972

emisario de la muerte $\mathrm{y}$, finalmente, la lucha que se da entre ambas por la vida de la protagonista (ver figura 3).

La figura de Leely, dentro del sueño, se explica en términos psicoanalíticos como uno de los desdoblamientos del yo de Neve; en este caso, el superyó que permanece consciente y hace a la protagonista despertar cuando el sueño se torna en pesadilla; sin embargo, para el volumen número siete el matiz religioso se visibiliza cuando la propia Leely se presenta como el guardián de Neve:

Leely: Esto es lo que en realidad soy. Neve... mírame sin miedo. Soy tu guardián. Mi labor en este lugar es regresarte a tu mundo original... Para eso necesitaba que entendieras lo que significa perder a alguien importante. Tu corazón ahora está listo para volver... La mujer que apareció en tu cuarto era un emisario del mundo del descanso eterno. Tenía la misión de terminar con tu vida... ése día sellé su esencia, es momento de usarla para abrir el camino de regreso (Velásco, 2007, pp. 43-49).

La idea del ángel custodio proviene del antiguo testamento y hace referencia al ángel que cuidaba el paraíso, el cual, según Zuriaga (2010), “se concretará con posterioridad en advocación como protector de lugares, ciudades, naciones o reinos” (p. 279). Este mismo autor expresa que fue después del Concilio de Trento cuando el Magisterio de la Iglesia definió las particularidades del ángel guardián en libros como el del padre Francesco Albertino de Catazao, S. J, Trattato del'l angelo custode, publicado en 1612; el P. de Barry, Devotion aux anges; el P. Segneri, Sermons l'ange guardien, entre otros (2010). Así, "la idea fundamental de estos textos es que un ángel nos acoge al nacer y nos ama desde nuestra infancia. Camina a nuestro lado, vela por nosotros, y sin que lo sepamos, aparta de nosotros la muerte" (Zuriaga, 2010, p. 283).

En el último volumen de Drem, Leely enfrenta y ahuyenta al emisario de la muerte que venía por Neve. Este episodio puede ser leído desde dos ópticas: Leely como el superego de Neve, quien la despierta cuando el sueño se vuelve pesadilla, o Leely como su ángel guardián protector que ahuyenta a la muerte. Si bien la primera suposición no puede ser considerada errónea, la segunda se refuerza por el hecho de que la propia Leely le dice a Neve que su misión es cuidarla mientras despliega sus alas de ángel y la lleva a la consciencia $\mathrm{y}$ al mundo real. 


\section{Revista Iberoamericana \\ de las Ciencias Sociales y \\ Humanísticas}

ISSN: $2395-7972$

En el punto contrario de Leely se encuentra otra figura: la mujer de largo cabello que se le aparece a Neve en el último volumen para invitarla a regresar al mundo de oscuridad y agua, al cual ella viajaba dentro del sueño. Como ya se dijo, el simbolismo de las aguas remite a la madre, espacio que le recuerda su propia madre perdida a la protagonista, lugar de evasión; sin embargo, la oscuridad y el agua también remiten al inframundo, así como la propia mujer que invita a Neve a dormir. Desde esta perspectiva, se encontraron dos lecturas para esta figura: la psicológica, donde la chica es otro desdoblamiento de la conciencia de Neve, es decir, la parte que no quiere despertar ni hacer conciencia (la parte del yo que hace que el sueño se torne en pesadilla); la segunda lectura se vincula a la religión, dentro de la cual la chica, como figura femenina, se halla ligada al inframundo ${ }^{4}$ y busca la muerte y el alma de Neve.

Esta polarización entre Leely y la mujer que aparece en el cuarto de la protagonista (su pelea por la vida o la muerte de Neve) remite a la creencia compartida entre cristianos y protestantes, quienes pensaban que el mal que acecha al ser humano cobra especial fuerza en el instante de la muerte, momento en el cual se lleva a cabo una pelea entre el demonio y los ángeles por el alma del moribundo, aspecto que se reflejaba en los Ars Moriendi o Manuales de la buena muerte, los cuales, según Handl Ugarte (2013)

[Estos manuales] surgieron en el siglo XV, acompañados de imágenes que ilustraban sus enseñanzas. Fomentaban una actitud valiente, pacífica y positiva ante la muerte. Esta se presentaba como la última batalla del hombre y la salvación de su alma, enfrentando las tentaciones de los demonios, ayudado por las buenas inspiraciones ofrecidas por su ángel de la guarda (pp. 89-108).

En Drem, efectivamente, la mujer de cabellos largos que surge de la pared tienta a Neve con el olvido y la tranquilidad, mientras que su guardián Leely ahuyenta a dicho ser y la ayuda a despertar. Sin embargo, en el manga esta batalla entre bien y mal por el alma humana presenta variantes: desde en el principio, pese a que la mujer del inframundo se vincula con algo negativo y oscuro, nunca se plantea que sea un demonio que quiere llevar a Neve al infierno, sino un enviado del más allá que quiere llevarla a la muerte. El papel de

\footnotetext{
${ }^{4}$ Dentro del taoísmo y el yin yang, la figura femenina se vincula a la noche, la oscuridad, el inframundo; la mujer es el yin.
} 


\section{Revista Iberoamericana \\ de las Ciencias Sociales y \\ Humanísticas}

ISSN: $2395-7972$

Leely como ángel guardián que aconseja positivamente y salva a su protegida se mantiene sin cambios.

La lucha entre bien y mal se halla presente no obstante, mientras que la presencia de este elemento religioso que se vuelve imperioso en el último volumen nos vuelve a remitir a las características de la posmodernidad, ya que debido a dichos aspectos, la historia pasa de un plano psicológico y onírico a uno religiosos, sin previo aviso, y luego del plano religioso al psicológico. Se trata, por tanto, de una transposición de planos que se presentan fragmentariamente conforme avanza la historia.

\section{Conclusiones}

Las manifestaciones de hibridez abundan en Drem y son visibles dentro de la narrativa y gráfica, así como en el aspecto físico de la edición. En este sentido, se destaca primero la tendencia de esta historieta a retomar elementos conceptuales del cuento fantástico, ya que - como se mencionó con anterioridad - convergen tanto el cuento fantástico tradicional como el moderno, punto de encuentro que nos lleva de nuevo a la posmodernidad. Al respecto, conviene recordar que esta última, según García Canclini, aparece cuando se dan vínculos entre la tradición y la modernidad, lo cual deja un entramado de ambas, punto donde aparece la posmodernidad creada a partir de los retazos: hibridez por excelencia, pastiche entre las dos primeras.

En Drem, el primer síntoma de lo fantástico aparece de manera externa a la cotidianeidad de Neve y continúa a lo largo de toda la historia hasta que el lector se percata de que todo es un sueño; entonces, es difícil precisar en qué instante lo tradicional pasa a lo moderno, ya que ambos al parecer son interdependientes. La posmodernidad en este punto flota entre lo tradicional y lo moderno; expresa su presencia mediante las rupturas espaciales y temporales, el desdoblamiento del yo, los fragmentos de la realidad que se sobreponen y se disimulan dentro de una aparente línea narrativa, la cual solo existe hasta el final de la historia.

Un segundo síntoma de la hibridez se da en el cruce temático que presenta la historia. Aunque aparentemente todo se explica desde lo psicológico, ya que Neve está soñando, dentro de lo onírico aparece el factor religioso con la presencia del ángel guardián, el emisario de la muerte y su correspondiente lucha por la vida de la protagonista. Si bien ambos se 


\section{Revista Iberoamericana \\ de las Ciencias Sociales y \\ Humanísticas}

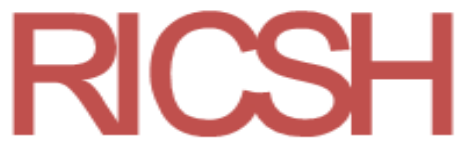

ISSN: $2395-7972$

explican como desdoblamientos del yo de Neve, es necesario destacar que dentro del sueño, cuando el emisario de la muerte logra atrapar a Neve, en la realidad ella muere; es revivida por los médicos luego de que en el sueño Leely enfrenta a dicho emisario y salva a la protagonista. El hecho de que dentro de la historia haya repercusiones de lo que pasa en el sueño genera confusión entre si esa parte del sueño es en realidad un sueño o en verdad se da la lucha entre el bien y el mal.

De manera que la mezcla entre el aspecto psicológico y religioso permite un nuevo punto de mezcla entre elementos diferentes y nos llevan nuevamente a lo tradicional y lo moderno: el aspecto religioso como característica de lo primero, el psicoanálisis y la psicología como uno de los ejes rectores de la modernidad. Y la posmodernidad, nadando también entre ambos, en los puntos en los que ambos permanecen sin ceder espacio al otro, sin que uno de los dos se disuelva. Pero esta hibridez no está integrada a la perfección debido a que la presencia de elementos diferentes, como lo religioso y lo psicológico, no se mezcla de manera perfecta, sino que aparecen desgarrados, y la presencia del factor religioso parece no cuadrar del todo en el perfecto universo psicológico de Drem.

En Drem se evidencian varias nociones de la posmodernidad: la de Jameson como dominante cultural y la de García Canclini, la cual se propone como producto de la mezcla entre lo moderno y lo tradicional; esto último debido a que la modernidad llegó a América Latina de manera desigual como proyecto modernizador inacabado en donde la tradición no desapareció y la modernidad no terminó de imponerse, lo que resultó — como se ve en Drem - en la constante mezcla de religión y ciencia, cristianismo y psicoanálisis. La hibridez entre ambos dio paso a la posmodernidad.

México, desde su modernidad y periferia, retomó elementos y fragmentos de la gráfica japonesa, ya híbrida de por sí. "El discurso construido desde la periferia recicla restos de las voces de la metrópolis y los suma a su propia voz, inventando así un derrotero particular; viaje iniciático desde la transgresión y la revuelta” (Lorenzano, 2009, p. 228). Dicho discurso, construido a pesar de sus contradicciones, se logró hibridar desde el tema del sueño de la protagonista del relato, ya que al leer Drem el espectador no se puede decidir por una explicación u otra: o todo es obra de su sueño y los actantes que se presentan son únicamente consecuencia del desdoblamiento de su yo, o sí es un sueño, pero dentro del elemento mágico religioso se toma como verdadero y, entonces, Leely sí es el ángel de la guarda que protege a Neve de la muerte. 


\section{Revista Iberoamericana \\ de las Ciencias Sociales y \\ Humanísticas}

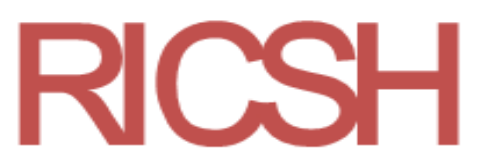

ISSN: 2395 - 7972

En esta historieta, el factor posmoderno se presenta principalmente con la hibridez de la modernidad y la tradición, la cual será la dominante cultural en los primeros seis volúmenes de Drem, así como en la primera mitad del séptimo. Sin embargo, en la última mitad del último volumen, la situación da un giro y la dominante cultural se vuelve la modernidad. En ese punto Neve despierta y entonces lo fantástico se disuelve: las rupturas espaciales y temporales, así como los desdoblamientos del yo desaparecen; en su lugar, queda una única trama lineal donde todo lo anterior se explica, al parecer, por el ámbito psicológico. Debido a lo anterior, en Drem se evidencia un juego donde los elementos tradicionales, modernos y posmodernos desaparecen, resurgen y se recrean de manera continua.

El último factor que remite a la hibridez en Drem no se desarrolla precisamente dentro de la historia, sino se refiere a sus características: el estilo del manga japonés, en su gráfica y desarrollo, así como la caracterización de lo mexicano, que en la historieta se queda únicamente en el entorno urbano en el que se desarrolla la historia. Efectivamente, por donde se revise, Drem es un manga: los personajes dibujados con simplicidad y expresividad propia de este medio japonés, el manejo del vacío y el predominio de la imagen sobre el texto, ya que hay diálogos pequeños que se desarrollan en más de seis páginas; además de lo anterior, existe el uso de la línea con fines expresivos, la distorsión en el rostro de los personajes para denotar emociones fuertes, etc.

Es necesario enfatizar que Drem es un cómic más complejo de lo que parece a primera instancia. En este sentido, es interesante el modo en el que el sujeto de la historia (Neve) se desdobla en una gran cantidad de personajes que son sus conocidos y quienes le provocan seguridad en situaciones y lugares en los que también se siente cómoda; su ambiente en el sueño la conforta y la mayor parte del tiempo aleja las pesadillas.

En síntesis, se puede decir que se trata de un personaje complejo que va evolucionando y transformándose a través del dolor de la realidad y el provocado por sus pesadillas. De los personajes que la acompañan, evoluciona también Leely, pero sin olvidar que esa Leely que el lector conoce, la mayor parte del tiempo, es la que recrea Neve en su mente y una parte de ella misma. Entonces, ¿cómo es la verdadera Leely? Se conoce muy poco de ella en el último tomo como para saber qué tanto corresponde al ideal de la mente de Neve. Lo mismo pasa con Noah, quien no cambia ni evoluciona en toda la historia ni dentro del sueño. De hecho, fuera de este tampoco se sabe lo suficiente de él como para comprender su transformación. 


\section{Revista Iberoamericana \\ de las Ciencias Sociales y \\ Humanísticas}

ISSN: 2395 - 7972

Drem no es un producto aislado, pues se creó en un momento en el que después de la apertura de fronteras propia de la implantación del neoliberalismo en México se introdujeron toda una serie de productos extranjeros, entre ellos el manga y el anime japonés, que importaron nuevas narrativas y formas de hacer gráfica en el cómic. Este manga mexicano fue creado como producto de una serie de reconversiones realizadas por una persona; surgió por la habilidad y creatividad de Lorena, quien fusionó la estética y el modo de producción de una serie de productos japoneses que ya eran híbridos, pero con aspectos personales, escenarios mexicanos y experiencias subjetivas que al mezclarse dieron paso a una serie de nuevos productos, los cuales compiten codo a codo con la mercancía importada.

Finalmente, solo queda destacar que Drem fue creado en un momento propicio en el que el contacto con productos extranjeros facilitó la interrelación con otras culturas. Se trata de una cultura que exalta lo heterogéneo y lo diferente al mismo tiempo que intenta globalizar; un momento en donde la hibridez, característica de toda cultura humana, se acentúa debido a la tendencia a las mezclas propias del contexto actual, en la que lo posmoderno es la dominante cultural que rige buena parte de las producciones culturales del hoy. 


\section{Revista Iberoamericana \\ de las Ciencias Sociales y \\ Humanísticas}

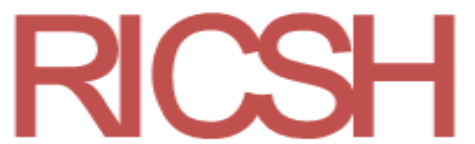

ISSN: $2395-7972$

\section{Referencias}

Bolívar Echeverría, B. (2000). La modernidad de lo barroco. México: Era.

Brigitte, R. (2008). Mil años de manga. Barcelona: Mondadori.

Calabrese, O. (1999). La era neobarroca. Madrid: Cátedra.

Castelli Olvera, S. I. (2017). La introducción en influencia del manga en México: el caso de Lorena Velásco Terán y DREM. Cuco, Cuadernos de Cómic, (8). Recuperado de http://cuadernosdecomic.com/docs/revista8/La_introduccion_e_influencia_del_man ga_en_Mexico_El_caso_de_Lorena_Velasco_Teran_y_DREM.pdf.

Cobos, T. (2010). Animación japonesa y globalización: la latinización y la subcultura otaku en América latina. Razón y Palabra, 15(72), 1-28.

Cooper, J. C. (2004). Diccionario de símbolos. Barcelona: Gustavo Gili.

Domínguez, V. (2002). La cabeza de medusa, el miedo, el espejo y la muerte. En Domínguez, V. (ed.), Los dominios del miedo. Madrid: Biblioteca Nueva.

Freud, S. (2013). La interpretación de los sueños. Madrid: Akal.

García Canclini, N. (2009). Culturas híbridas. México: Mondadori.

García Rodríguez, A. (2005). Cultura popular y grabado en Japón siglos XVII al XIX. México: El Colegio de México.

García Rodríguez, A. (2009). Cultura visual. Once estudios iberoamericanos. México: Colegio de México.

García Rodríguez, A. (2011). Control de la estampa erótica japonesa shunga. México: El Colegio de México.

Ginzburg, C. (1999). Mitos, emblemas e indicios, morfología e historia. Barcelona: Gedisa.

Handl Ugarte, A. L. (2013). Ars bene moriendi: el arte de la buena muerte. Revista Chilena de Estudios Medievales, (3), 89-108.

Jameson, F. (1998). El giro cultural: escritos seleccionados sobre posmodernismo. Buenos Aires: Manantial. 


\section{Revista Iberoamericana \\ de las Ciencias Sociales y \\ Humanísticas}

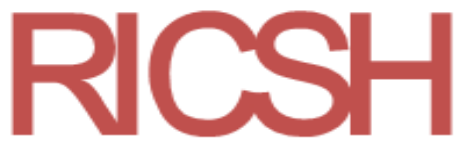

ISSN: 2395 - 7972

Jameson, F. (2005). La lógica cultural del capitalismo tardío. Centro de Asesoría y Estudios Sociales. Recuperado

de http://www.caesasociacion.org/area_pensamiento/estetica_postmaterialismo_negri/l ogica_cultural_capitalismo_tardio_solo_texto.pdf.

Lacan, J. (2009). El estadío del espejo como formador del yo (je) tal como se nos revela en la experiencia piscoanalítica. Escritos $I$.

Larrañaga, J. (2017). De la obra a la multiplicidad, sobre la investigación univesitaria del arte. México: CENIDIAP.

Lobo, E. (2010). El fenómeno del doble y su relación con lo siniestro. Nous, L'Aperiódic Virtual de la secció Clínica de Barcelona.

Lorenzano, S. (2009). Posmodernidad. En Szurmuk, M. y McKee, R. (coords.), Diccionario de estudios culturales latinoamericanos. México: Siglo XXI.

Metz, C. (1977). El significante imaginario. Barcelona: Paidós.

Muñoz Rangel, J. J. (2010). La narrativa fantástica en el siglo XXI. Ínsula, (765).

Nieto, O. (2015). Teoría general de lo fantástico. Del clásico al posmoderno. México: Universidad Autónoma de la Ciudad de México.

Papalini, V. (2006). Anime. Mundos tecnológicos, animación japonesa e imaginario social. Buenos Aires: La Crujía.

Poloniato, A. (2008). Percepción (posmoderna) y el hacer sentido en el anime. Anuario de Investigación, 680-702.

Schodt, F. (1983). Manga, manga! The world of japanese comics. Tokyo: Kodansha.

Velásco Terán, L. (2007). DREM, 7. México: Estudio Syanne.

Velasco Terán, L. (2008). DREM, 1. México: Estudio Syanne.

Zuriaga, V. F. (2010). Memorias del V Encuentro Internacional sobre Barroco. Entre la tierra y el cielo, el tipo iconográfico del ángel custodio. La Paz. 